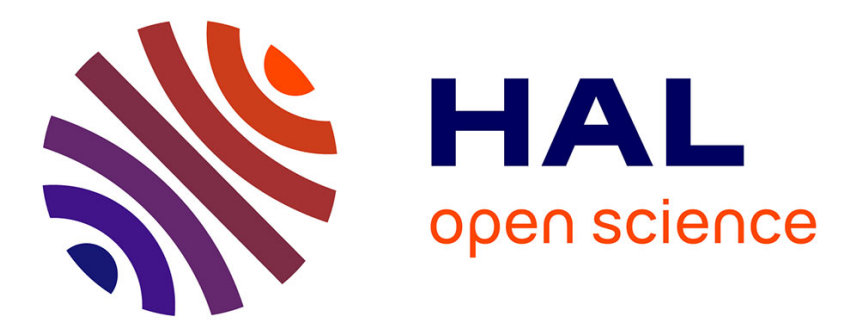

\title{
Development of a tool design method in cross wedge rolling: description and applications
}

Catalina Gutierrez, Philippe Mangin, Laurent Langlois, Régis Bigot

\section{To cite this version:}

Catalina Gutierrez, Philippe Mangin, Laurent Langlois, Régis Bigot. Development of a tool design method in cross wedge rolling: description and applications. Key Engineering Materials, 2014, 611612, pp.1694-1701. 10.4028/www.scientific.net/KEM.611-612.1694 . hal-01105099

\section{HAL Id: hal-01105099 \\ https://hal.science/hal-01105099}

Submitted on 4 Feb 2015

HAL is a multi-disciplinary open access archive for the deposit and dissemination of scientific research documents, whether they are published or not. The documents may come from teaching and research institutions in France or abroad, or from public or private research centers.
L'archive ouverte pluridisciplinaire HAL, est destinée au dépôt et à la diffusion de documents scientifiques de niveau recherche, publiés ou non, émanant des établissements d'enseignement et de recherche français ou étrangers, des laboratoires publics ou privés. 


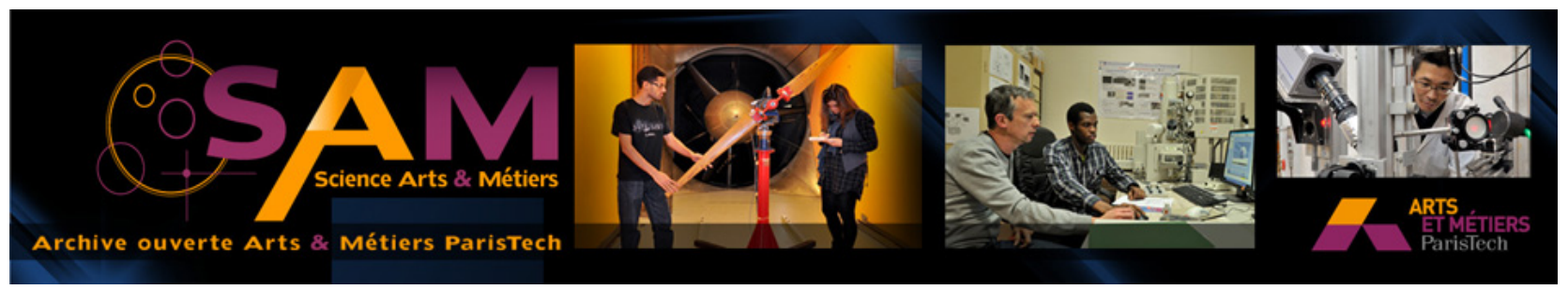

Science Arts \& Métiers (SAM)

is an open access repository that collects the work of Arts et Métiers ParisTech researchers and makes it freely available over the web where possible.

This is an author-deposited version published in: http://sam.ensam.eu

Handle ID: .http://hdl.handle.net/10985/9237

\section{To cite this version :}

Catalina GUTIERREZ, Philippe MANGIN, Laurent LANGLOIS, Régis BIGOT - Development of a tool design method in cross wedge rolling: description and applications - Key Engineering Materials - Vol. 611-612, p.1694-1701 - 2014 


\title{
Development of a tool design method in cross wedge rolling: description and applications
}

\author{
Catalina GUTIERREZ ${ }^{1,}$, , Philippe MANGIN ${ }^{1, b}$, Laurent LANGLOIS ${ }^{1, c}$; \\ Régis BIGOT ${ }^{1, d}$ \\ ${ }^{1} 4$ rue Augustin Fresnel, Art et Métiers, 57078, Metz, France \\ accatalina.gutierrez@ensam.eu, bphilippe.mangin@ensam.eu, 'laurent.langlois@ensam.eu, \\ 'regis.bigot@ensam.eu
}

Keywords: Cross wedge rolling, tool design methodology.

\begin{abstract}
Till now, the definition of cross wedge rolling dies requires know-how and important expertise from the designers. A decision-making methodology is being developed to provide sequential and logical steps to draw easier and faster the tool geometry. This methodology is based on designing rules found in literature that link the geometrical parameters of the desired rolled part and the geometrical parameters of the tool. Nevertheless, in the literature, the rules are not always consistent because the admissible domain for a parameter can differ from one author to another. In order to take into account this variability, a stability index is associated to each rule and to the designed tool. The methodology allows updating of the existing rules and the implementation of new rules. The set of parameters defining the geometry of the tool can be exported in the $\mathrm{CAD} / \mathrm{CAM}$ software and FEM software. A case-study is presented to illustrate and validate the methodology.
\end{abstract}

\section{Introduction}

The Cross Wedge Rolling process (CWR) is a metal forming process in which a cylindrical billet is plastically deformed into another axisymmetrical shape by the action of wedge segments, moving tangentially relative to each other. The movement of the wedges causes a progressive spread in the axial direction of the billet and a reduction in its cross-sectional area; it can be of simple diameter reduction or of several reductions. Two main configurations are industrially developed as shown in Fig. 1.
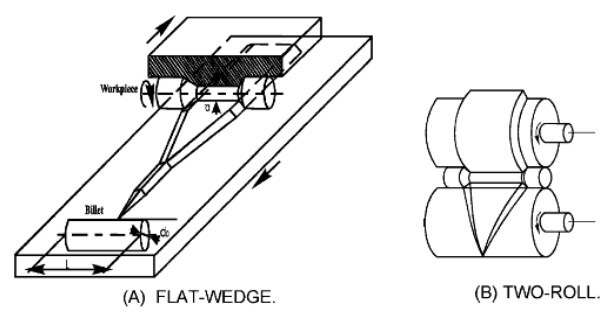

Figure 1 - a) flat-type CWR process, b) roller-type CWR process [1]

The benefits of the CWR process, compared to other traditional forming methods, have been listed by several authors. For [1], CWR is a material and energy - saving process with lower levels of noise and lower environmental impact. For [2] some of the advantages are: the improvements in product quality (fine tolerances, fiber structure), a higher productivity (cycle time up to $5-10 \mathrm{sec}$ ) and a high accuracy and maximum proximity to required dimensions of finished products.

In comparison with other metal forming processes, CWR is in commercial terms relatively new. The CWR process has been most likely developed in Eastern Europe (e.g. Russia, Belarus, Poland and Czech Republic) Japan and China. The communicating and translating difficulties are some of the reasons of the low and slow entry of this technology in Western Europe [3].

At the Yokohama National University, Masujiro Hayama published his work on optimum working conditions in the CWR of stepped shaft [4]. He proposed the optimum reduction in cross-sectional 
area of rod and the effective range of basic angles (forming and spreading angles) of the tool wedge. In 1998, [5] from the Fraunhofer Institute for Machine Tools and Forming Technology in Chemnitz-Germany conducted the research work on the optimization of main parameters and the CWR machine's design. At the Lodz Technical University, Pater presented his work on the determination of the ranges of basic parameters for tool segments in order to avoid principal defects presented on the process (e.g necking, central cavities) [6]. At the University of Pittsburg in United States, Lovell and Li carried out investigations on the morphology of internal defects in cross wedge rolling and the influence of main parameters [2].

\section{Cross-wedge rolling process}

Due to the amount of parameters involved and its tridimensional nature, CWR is a complex process only stable within some specific bounds [7]. The difficulty relies in the relationship between the parameters that can be specific and different for each case. In a global scale, the parameters of interest of the CWR process can be classified in two main groups: geometrical parameters, such as the die's geometry (parameters listed in Fig. 2); and forming parameters, such as the required load, rolling rate, friction effect and strain, material, initial temperature of the billet, contact pressure, among others [7].

A wedge can be defined by the following parameters (Fig. 2):
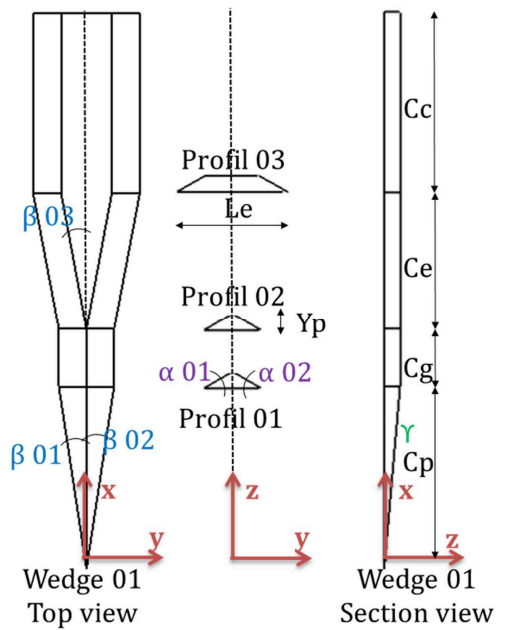

Table 1 - Parameters of die configuration

\begin{tabular}{|lll|}
\hline$\alpha$ & {$\left[^{\circ}\right]$} & forming angle \\
\hline$\beta$ & {$\left[^{\circ}\right]$} & spreading angle \\
\hline$\gamma$ & {$\left[^{\circ}\right]$} & ramp angle \\
\hline$C_{p}$ & {$[\mathrm{~mm}]$} & knifing zone \\
\hline$C_{g}$ & {$[\mathrm{~mm}]$} & guiding zone \\
\hline$C_{e}$ & {$[\mathrm{~mm}]$} & forming zone \\
\hline$C_{c}$ & {$[\mathrm{~mm}]$} & sizing zone \\
\hline$d_{i}$ & {$[\mathrm{~mm}]$} & billet diameter \\
\hline$d_{\min }$ & {$[\mathrm{mm}]$} & final diameter \\
\hline$Y_{p}$ & {$[\mathrm{~mm}]$} & wedge height \\
\hline$l_{e}$ & {$[\mathrm{~mm}]$} & spacing of the wedge \\
\hline
\end{tabular}

Figure 2 - Geometrical parameters of die configuration

The billet is put in position at the beginning of the knifing zone. Once the wedges start to move, the tools bite into the surface of the billet and reduce its diameter to the required portion diameter. Movement is transmitted by the adherence of the billet to the wedges, creating a force torque making the billet to rotate around its longitudinal axis. Trybological phenomena are then of high importance, giving the role of surface texture of the wedges in the magnitude of the transmissible torque, contact condition and slip phenomena.

The forming zone, the zone which gives shape to the workpiece, is the most important part of the tool. In this zone the workpiece is plastically deformed, being forced to flow to the ends of the tool. During forming, the surface deformation is propagated to the interior. At this point, some parts of the workpiece are under stress conditions: compressive, tensile and shear strain; and some parts are only in movement: rotation and translation.

The forming angle $\alpha$ and the spreading angle $\beta$ (see Fig. 2) determine the size of the contact area between the tools and the workpiece; and the amount of axial deformation experienced by the workpiece. In this contact strong tangential and normal stresses occur. 
Cross-wedge rolling failures. At a global scale, the difficulty relies on the amount of parameters involved in the process that must be correctly chosen in order to avoid failures. Slight variations in basic parameters can have a high impact on the part.

According to several authors [2] [3], defects in CWR products can be classified in three groups (see Fig. 3): improper forming of a section, external defects and internal defects. According to [1] these failures are repeatable when encountered at a specific set of operating conditions. This subject is fully described and discussed in the research works done by [2] [3].

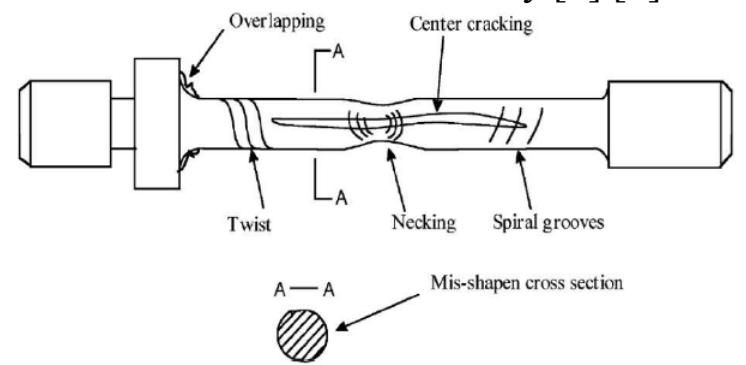

Figure 3- Common defects on CWR products [2]

\section{Cross-Wedge rolling tool design methods}

CWR application and evolution remains quite undeveloped in Western Europe, France in particular, despite all its known advantages. Several reasons are listed below:

- CWR tool design has been based on the experience and intuition of designers.

- It has a high degree of technological complexity.

- Little work has been done in the automation and in rational and systematic methods of die design. Moreover, there are no decision-making tools publicly available to the date.

- Industry has been developing and working with forging rolling process.

- Very few researches and studies for CWR development.

Theoretical and experimental research has been conducted in the aim of solving difficulties in implementing the CWR process in industrial conditions and the automation of the wedge designing method. Some of the different design approaches are: [8] and [9]. It should be noted that most of the designing methods are developed privately and access to information related to it, is not easy.

COLT method (Conception d'Outillage de Laminage Transversal COLT for its initials in French), is a decision supporting tool for the designing of the die in cross wedge rolling (CWR). This methodology is being developed to provide sequential and logical steps to draw easier and faster the die geometry. COLT is based on the parametric definition of the desired rolled part, in the first place; and on the parametric definition of the tool, in the second place. The two corresponding sets of parameters are then linked through design rules.

Description of the CWR tool design procedure COLT. The aim of the COLT method is to allow a CWR expert or non-expert user to obtain the geometric parameters of the wedge by inputting the geometric characteristics of the desired part.

This procedure is based on a sequence of logical steps as well as a series of criteria to be satisfied. COLT aims to integrate the state of art as much as possible. It also seeks to be a flexible tool, by allowing the updating of the already existing rules and the implementation of new design rules. The main steps of the COLT method according to this latest version (V02) are:

- A11. Collect the specifications of the part. Definition of the CWR tool structure

- A12. Characteristics of the machine

- A13. Characteristics of the billet

- A14. Characteristics of the part 
- A15 and A16. Definition of wedges

- A17 and A18. Definition of remarkable point's coordinates

Each of these stages encompasses another series of steps, at a more detailed level; and for each of these steps there are: an input data, a defined action, an output data and a number of rules to verify.

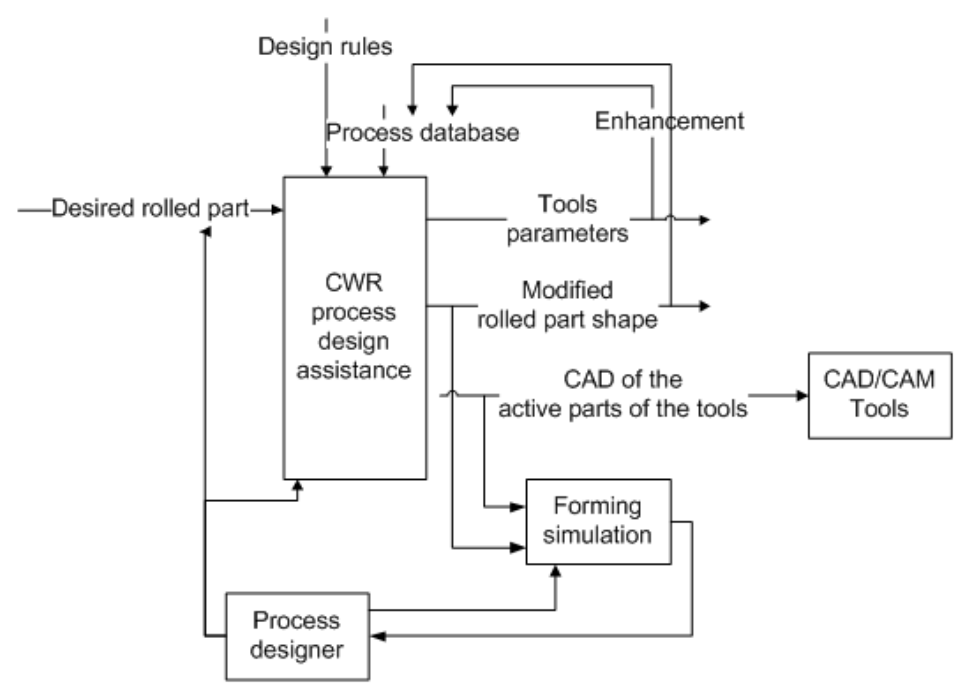

Figure 4- Global approach of the COLT method [10]

Rules and stability index. COLT method is based on a synthesis of literature rules as well as rules identified during experimental work. Throughout the method, at each step, this design rules have to be validated in order to proceed to the following step.

The designing rules allow choosing the basic parameters of the wedge. Some of these rules are implemented in order to avoid specific CWR defects, while others correspond to geometrical relations between the parameters.

Nevertheless, in the literature, the rules are not always consistent because the admissible domain of variation for a parameter can differ from one author to another. In order to take into account this variability, the concept of stability index is introduced.

The stability index is associated to each rule, this one being a function of the parameters concerned by the rule. The maximum stability index will be attributed when all the authors/rules agree the value of the parameter is within the correct limits.

Example: the acceptable limits of the forming angle $\alpha$ have been established by several authors: (see Table 2 and Fig. 5)

Table 2 - Acceptable limits of the forming angle by different references

\begin{tabular}{|c|c|c|}
\hline $\min \left[{ }^{\circ}\right]$ & $\max \left[^{\circ}{ }\right]$ & reference \\
\hline 20 & 45 & {$[11]$} \\
\hline 10 & 55 & {$[4]$} \\
\hline 10 & 40 & {$[6]$} \\
\hline 20 & 60 & {$[12]$} \\
\hline 15 & 40 & {$[3]$} \\
\hline 15 & 60 & {$[7]$} \\
\hline 20 & 87 & {$[13]$} \\
\hline
\end{tabular}

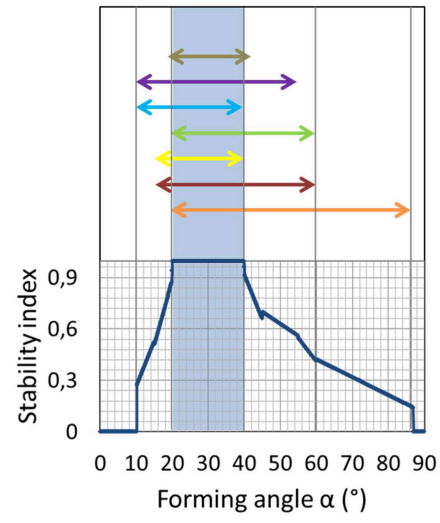

Figure 5- Stability index function of forming angle $\alpha$ 
In order to evaluate the different sources, the concept of maturity is used. It allows to weight the sources according to the judgment we make about the author.

Referencing to the geometrical parameters of a wedge, as it is shown in Fig. 2, three axial sections can be observed along the rolling length which are called profiles. These profiles are located at the beginning/end of each zone (i.e. knifing, guiding, forming and sizing zones) and each of them can be assumed as the sum of basic elements e.g. height, length, angles and radius edges and remarkable points. The axial profile of the reduced diameter section in the part matches to the final profile of the wedge.

The COLT method will output the coordinates(x,y,z) of the remarkable points as shown in Fig. 6, calculated through geometrical equations. The full amount of points will define the wedge and will integrate all the geometrical parameters previously enlisted.

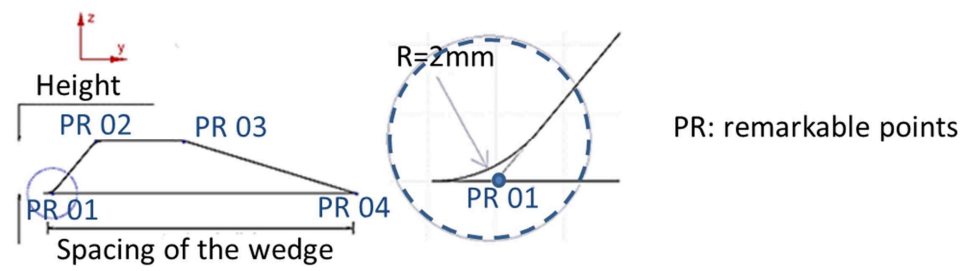

Figure 6- Example of remarkable points

If the part consists of more than a simple diameter reduction, then each portion corresponds to one wedge and the relative positions of the different portions will determine de relative position of the wedges.

\section{Demonstration example}

A simple reduction part is presented in this article in order to explain the COLT method (see Fig. 7).

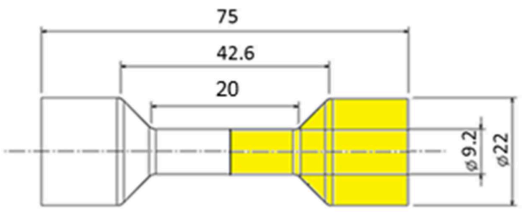

Figure 7 - Simple reduction part

A11. (1) Collect the specifications of the part.

(2) Definition of the CWR tool structure.

If the part is longitudinal asymmetric, the COLT method will demand to perform a symmetry throughout its axial axis. Once the part is longitudinal symmetric, the part is classified.

Based on the work by [14], parts can be classified in three main types as well as wedges can be classified in four main types. A relationship between the type of parts and the type of wedges has been made, consequently once a part has been classified, the corresponding wedges are associated.

Following this approach, the structure of the CWR die is one main wedge.

A12. Characteristics of the machine.

The machine available is a flat type with a maximum length of $220 \mathrm{~mm}$. The maximum diameter of the billet accepted is $100 \mathrm{~mm}$.

A13. Characteristics of the billet.

For calculating the billet's dimensions, the volume of the part is needed. The first assumption made is that the maximum diameter of the part is the diameter of the billet.

The length of the billet is solved in the equation of a cylinder, using the volume of the part and the diameter of the billet. The thermal expansion is then considered. 
Once the dimensions are selected, it is necessary to confirm that the billet will at least perform 3 laps, in order to guarantee that at least at each rolling zone (knifing, forming and sizing zones) the billet will perform one lap, and so each part of the billet will be subject of the deformation.

The number of laps is calculated with the maximum length of the machine and the perimeter of the billet. In this case, the billet can perform 3.3 laps.

From the drawing of the part, it is possible to know the final diameter of the only portion: $9.2 \mathrm{~mm}$. At this stage the reduction ratios are validated. Authors use different reduction ratios, for example [4] use the optimum reduction in cross-section area $\mathrm{R}_{\mathrm{op}}$, [12] use the diameter reduction Ed; and relative reduction $\delta$ used by [6].

In this example, both Ed and $\mathrm{R}_{\mathrm{op}}$ were studied. $\delta$ is studied in the following stages when also verifying other designing criteria. The reduction ratios are $E d=0.56$ and $R_{o p}=0.60$, with stability index $I c=0.42$ and $I c=1$ respectively.

A15 and A16. Definition of wedges.

When starting the definition of the wedge, the first profile that can be determined is the one at the end of the sizing zone (profile 3). This profile is imposed by the dimensions of the part, that is to say the geometrical dimensions of the profile 3 are given by the geometrical dimensions of the groove (height, angles, length) of the part. During the sizing zone, the profile is constant, which means that the profile 2, at the beginning of the sizing zone it is the same as profile 3 and so the imposed profile (see Fig. 8).

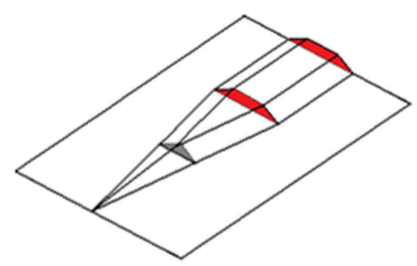

Figure 8 - Definition of wedges

The profile 1 at the end of the cutting zone has to be chosen. In this case, the height of the profile is imposed by the final diameter of the groove. First, the forming angles need to be chosen following the stability index function. Secondly, the spreading angles are chosen again following the stability index function correspondent. The user can return to the previously decision in order to change the forming and/or spreading angles values if the stability indexes are not acceptable. Thirdly, the length of the three zones (cutting, forming and sizing) will be determined by geometric constraints of: the forming angles, spreading angle, initial diameter of the billet and final diameter of the portion. If the rules imposing: one lap minimum by zone and respecting the maximum length available are not satisfied, the user can return to the previous designing stages, until finding a good combination of parameters.

Here below (Table 3), three different configurations of wedges are proposed. At the present COLT is not automated, which means, the user in modifying the parameters manually will search for acceptable stability indexes. In the future, the computer tool will output the optimum selection of parameters, having the higher stability indexes as permitted by the machine restrictions and the part's geometry.

Table 3 - Geometrical characteristics of 3 different wedges

\begin{tabular}{|c|c|c|c|c|c|c|c|c|c|c|c|c|c|c|}
\hline & \multicolumn{5}{|c|}{ Profile 1} & & \multicolumn{5}{|c|}{ Profile 2} & & & \\
\hline Configuration & $\begin{array}{l}\alpha 1 \\
\left.{ }^{\circ}\right]\end{array}$ & $\begin{array}{l}\alpha 2 \\
{\left[^{\circ}\right]}\end{array}$ & $\begin{array}{l}\beta 1 \\
{\left[^{\circ}\right]}\end{array}$ & $\begin{array}{c}\mathrm{Cp} \\
{[\mathrm{mm}]}\end{array}$ & tour & $\begin{array}{c}\mathrm{r} \\
{\left[^{\circ}\right]}\end{array}$ & $\begin{array}{l}\alpha 1 \\
{\left[{ }^{\circ}\right]}\end{array}$ & $\begin{array}{l}\alpha 2 \\
{\left[^{\circ}\right]}\end{array}$ & $\begin{array}{l}\beta 3 \\
{\left[^{\circ}\right]}\end{array}$ & $\begin{array}{c}\mathrm{Ce} \\
{[\mathrm{mm}]}\end{array}$ & tour & $\begin{array}{c}\mathrm{Cc} \\
{[\mathrm{mm}]}\end{array}$ & tour & $\begin{array}{c}\mathrm{N} \\
\text { total }\end{array}$ \\
\hline 1 & 30 & 30 & 8 & 78.87 & 1.14 & 4.6 & 30 & 30 & 8 & 71.15 & 1.03 & 69.97 & 1.01 & 3.18 \\
\hline 2 & 30 & 30 & 13 & 48.01 & 0.69 & 7.6 & 30 & 30 & I & 81.44 & 1.18 & 90.54 & 1.31 & 3.18 \\
\hline 3 & 20 & 20 & 12 & 82.73 & 1.20 & 4.6 & 30 & 30 & 8 & 7115 & 03 & 6612 & 0.96 & 3.18 \\
\hline
\end{tabular}


For each configuration the stability index of the geometrical parameters were evaluated. In Configuration 2 the length of the cutting zone is less than one lap and in configuration 3 the spreading angle of $12^{\circ}$ has a stability index below 0.6 . The configuration 1 is chosen (see Table 4).

Table 4 - Configuration 1: list of the parameters with the stability index associated

\begin{tabular}{|l|c|c|}
\hline Parameter & Value & Stability index \\
\hline Cp [lap] & 1.14 & 1 \\
\hline Ce [lap] & 1.03 & 1 \\
\hline Cc [lap] & 1.01 & 1 \\
\hline$\Upsilon\left[{ }^{\circ}\right]$ & 4.6 & 0.96 \\
\hline$\alpha 1$ and $\alpha 2$ profile $1\left[^{\circ}\right]$ & 30 & 1 \\
\hline$\beta 1$ profile $1\left[^{\circ}\right]$ & 8 & 1 \\
\hline$\alpha 3$ and $\alpha 4$ profile $2\left[^{\circ}\right]$ & 30 & 1 \\
\hline
\end{tabular}

Once the user has chosen the geometrical parameters of the wedge, the local coordinates $(\mathrm{x}, \mathrm{y}, \mathrm{z})$ of the remarkable points are calculated through geometrical equations. The Fig. 9 shows the remarkable points in the knifing profile of a main wedge and in Table 5 the coordinates of these points are indicated. The procedure is continued to calculate the local coordinates of all the remarkable points of the wedge.

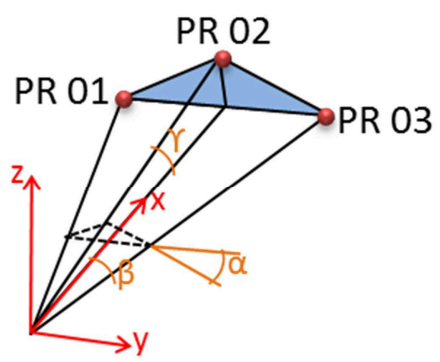

Table 5 - Local coordinates of the remarkable points in Fig. 9.

\begin{tabular}{|c|c|c|c|}
\hline $\begin{array}{c}\text { Remarkable } \\
\text { points }\end{array}$ & $\begin{array}{c}\mathrm{X} \\
{[\mathrm{mm}]}\end{array}$ & $\mathrm{Y}[\mathrm{mm}]$ & $\begin{array}{c}\mathrm{Z} \\
{[\mathrm{mm}]}\end{array}$ \\
\hline PR 01 & $C_{p}$ & $-Y_{p} / \tan (\propto)$ & 0 \\
\hline PR 02 & $C_{p}$ & 0 & $Y_{p}$ \\
\hline PR 03 & $C_{p}$ & $Y_{p} / \tan (\propto)$ & 0 \\
\hline
\end{tabular}

Figure 9 - Remarkable points in the knifing profile of a main wedge.

After obtaining all the local coordinates of each wedge of each reduced section of the part, the global coordinates are calculated according to the relative position of the portions. Also, as it was previously explained, because the part is longitudinally symmetric, only by replicating the designed wedges, the complete matrix is obtained.

\section{Conclusions}

A decision supporting tool for the designing of the tool in cross wedge rolling is presented in this paper. The methodology is based on a synthesis of literature rules as well as rules identified during experimental work. The designing rules allow choosing the basic parameters of the wedge. The concept of stability index is introduced in order to take into account the different admissible domain for a parameter that can vary from one author to another. A simple reduction part is used as a demonstration example.

One of the first advantages of this methodology is that the user will be able to have a first approach, still during the designing stage, of the stability of the process. The designing decisions of the user will be taken under the guidance of the COLT method relying on scientific and experimental bases. An additional advantage is the fact that COLT maintains the relationship between the wedge's parameters at all time. So the effect of a chosen parameter can be observed in the stability index of another parameter. This permits the user to observe the interaction and effects of its designing decisions. 
A third advantage is the flexibility of the methodology. The user can obtain different wedges by simply modifying one parameter. The coordinates of the remarkable points of the wedge are also modified because of the geometrical relationship established between all the parameters.

COLT seeks to be an interactive method. In the future development of the computer tool the bibliographical and experimental sources, as well as its maturity, can be modified, eliminated or even adding new sources. Subsequently, the experimental user can state its own designing rules.

A first computer tool is being developed; it is expected its implementation for an industrial case of a connecting rod preform.

\section{Acknowledgement}

This paper results from research project which is financially supported by CETIM Forge Committee and Région Lorraine. Special regards to Mr Pierre KRUMPIPE (CETIM) for his cooperative work. The authors are thankful to the IWU of Chemnitz for their scientific and technological support.

\section{References}

[1] Q. Li and M.R. Lovell, Cross wedge rolling failure mechanisms and industrial applications, International Journal of Advanced Manufacturing Technology, vol. 37 (2008) pp. 265-278.

[2] Q. Li, M.R. Lovell, W. Slaughter and T. Kaveh, Investigation of the morphology of internal defects in cross wedge rolling, Journal of Materials Processing Technology, no. 125-126 (2002) pp. 248-257.

[3] X.P. Fu and T.A. Dean, Past developments, current applications and trends in the cross wedge rolling process, International Journal of Machine Tools and Manufacture, vol. 33, no. 3 (June 1992) pp. 367-400.

[4] M. Hayama, Optimum Working Conditions In The Cross Rolling Of Stepped Shaft, Journal of Mechanical Working Technology, vol. 3 (1979) pp. 31--46.

[5] Neugebauer, Kolbe, and Riede, Sächsische Fachtagung Umformtechnik, in Optimierte verfahrensparameter und antriebskonzeptionen für das querwalzen, Chemnitz (1998) pp. 1-25.

[6] Zb. Pater, W. Weronskia, J. Kazaneckib, and A. Gontarza, Study of the process stability of cross wedge rolling, Materials processing technology, vol. 92- 93 (1999) pp. 458-462.

[7] W. Weronski and $\mathrm{Zb}$. Pater, Selection of geometric parameters of transverse wedge rolling tools, Journal of materials processing technology, vol. 34 (1992) pp. 273-280.

[8] Umbach, Pannasch and Lorenz, Entwicklungsfortschritte zum Querwalzen von Stahlwerkstoffen, Umformtechnik, vol. 3 (1995) pp. 173-175.

[9] Abramov, Preparation of input data for the numerical analysis of CWR process on the basis of the program-methodical complex "Rolling", Advanced methods and technologies for materials manufacture and processing. Theory and Practice of Cross Wedge Rolling, vol. 4, (2008) pp. 85-91.

[10] P. Mangin, L. Langlois and R. Bigot, Development of cross wedge rolling process in France: Industry requirements and academic work in ENSAM, Metz.

[11] G. Holub, Příčné klínové válcování, SNTL, p. 141 (1972) Czech.

[12] R Neugebauer, M. Kolbe and H. Riede, New warm forming processes to product hollow shafts, Journal of Materials Processing Technology, vol. 119 (2001) pp. 277-282.

[13] Claasen, Herlan, and Lorenz, Sächsische Fachtagung Umformtechnik, in Querwalzen Möglichkeiten und Kriterien, Freiberg (1995) pp. 16/1-16/34.

[14] X.P. Fu and T.A. Dean, Development of a knowledge-based sequence design system for cross wedge rolling, in Computers in engineering, Minneapolis (1994) pp. 203-211. 